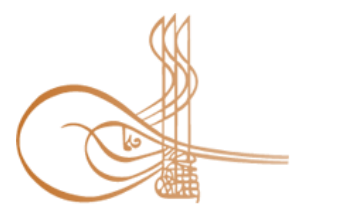

www.turkishstudies.net/economy
Turkish Studies - Economics, Finance, Politics

eISSN: 2667-5625

Research Article / Araștırma Makalesi

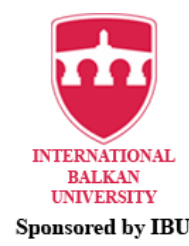

Sponsored by IBU

\title{
VUK, TFRS ve BOBI FRS'de Finansal Raporlama Farklılıklarının Finansal Tablolara Etkilerinin Karşılaştırılması: Farklar Üzerine Bir Uygulama
}

\author{
Comparasion Of Effects Of Financial Reporting Differences In Turkish Tax Proceduse Law \\ (VUK), TFRS And BOBI FRS On Financial Statement: An Application On Differences
}

\author{
Ali Kablan* - A. Engin Ergüden ${ }^{* *}$
}

\begin{abstract}
Standardization in financial reporting has become more important at global level in recent years. Financial Reporting Standarts For Large and Medium Enterprises (BOBI FRS) recently published by Turkish Public Oversight Accounting and Auditing Standarts Authority (KGK) has been made compulsory to apply in the preparation of the individual and consolidated financial statements of companies that are subject to independent audit but do not apply Turkish Accounting Standarts and Turkish Financial Reporting Standarts.In addition, all businesses operating in Turkey, the financial statements are prepared accordance with Turkish Tax Procedure Law (VUK). Companies which are subjected to independent auditing in Turkey must prepare their financial statements according to Turkish Tax Procedure Law (VUK).After then, optionally, converted and reclassified to financial statements according to Financial Reporting Standarts For Large and Medium Enterprises (BOBI FRS) or Turkish Financial Reporting Standarts (TFRS). At this point, accounting records regarding the translation transactions are made on the auditor's worksheets and not subject to the accounting information system. For this purpose, the disclosure regarding the differences between the financial statements of a company subject to independent audit and the financial statements prepared as a result of optional BOBI FRS or IFRS conversion transactions, is stated in the footnotes of Turkish Tax Procedure Law (VUK), Financial Reporting Standarts For Large and Medium Enterprises (BOBI FRS) and an application to show the differences in financial statements prepared in accordance with Turkish Financial Reporting Standarts. In the application included in the study, it is aimed to show the differences between financial statements prepared according to Turkish Tax Procedure Law (VUK) and financial statements prepared in accordance with Financial Reporting Standarts For Large and Medium Enterprises (BOBI FRS) and Turkish Financial Reporting Standarts.
\end{abstract}

Structed Abstract: Globalization has enabled world economies and societies to integrate into the world economy for faster economic growth and prosperity. Although globalization is seen by developing economies and some economic process observers as a process caused by large enterprises of developed countries, strong

*Dr. Öğr. Üyesi Trakya Üniversitesi, U.U.B.Y.O., Bankacılık ve Sigortacılık Bölümü

Assistant Professor, Trakya University, Uzunköprü School of Applied Sciences,Banking and Insurance

ORCID 0000-0003-2711-0034

alikablan@trakya.edu.tr

** Dr. Yarı Zamanlı Öğretim Görevlisi, CPA-CRMA

PhD, Part Time Lecturer, CPA-CRMA

ORCID 0000-0026-2011-2012

enginerguden69@gmail.com

Cite as/ Atıf: Kablan, A. \& Ergüden, A.E. (2020). VUK, TFRS ve BOBI FRS'de finansal raporlama farkl1lıklarının finansal tablolara etkilerinin karşılaştırılması: farklar üzerine bir uygulama. Turkish Studies - Economy, 15(3), 14271444. https://dx.doi.org/10.47644/TurkishStudies.43658

Received/Geliş: 17 May/Mayıs 2020

Accepted/Kabul: 15 September/Eylül 2020

Copyright $($ INTAC LTD, Turkey

Checked by plagiarism software

Published/Yayın: 25 September/Eylül 2020

CC BY-NC 4.0 
market place effect triggers globalization. In spite of the increasingly negative criticism that has been done for more than 30 years, the globalization movement cannot be prevented and the globalization trend continues at an increasing rate. It seems that this trend will continue for another predictable time in the future. The impact of globalization on the future formation of international accounting standards will be high. The accounting profession, which has a vital function in maintaining the healthy functions of companies all over the world, took the first step towards global accounting standards in 1972. With the support of great developments in computer and communication in the past half century, doing business with any corner of the world has become much easier, and societies have started to move towards a world where borders have been lifted.

The International Accounting Standards Board (IASB) is one of the organizations that work to harmonize financial reporting schemes at the international level. The start of IASB is based on the International Accounting Standard Committee (IASC). IASC; It was founded in 1973 as a result of an agreement signed by accounting organizations in Australia, Canada, France, Germany, Japan, Mexico, the Netherlands, England, Ireland and the USA. The purpose of IASC is to develop single and high quality, understandable and applicable global accounting standards in the public interest, in general purpose financial statements that require transparent and comparable information. IASC aims to bring the accounting standards across the world together by working with the national accounting standard makers. IASC was restructured in 2001 and left its place to IASB, and International Accounting Standards (IAS) left to IFRS.

In the first meetings of IASB held between 18-20 April 2001, it approved all the IAS and related comments that were issued before. It was decided that IAS issued by IASC will be valid until someone else replaces it and that IAS is called IFRS. Factors that require international harmonization in accounting; The internationalization of capital markets, the emergence of multinational companies, the establishment of audit firms operating in the international arena, and the efforts to establish economic unity can be gathered under the titles.

(i) Internationalization of Capital Markets: As a result of the liberalization of international trade and fund flows, many companies are listed on foreign exchanges and the share of foreign investors in the stock exchanges is gradually increasing. This situation has resulted in the internationalization of capital markets and has revealed that the financial statements of companies seeking funding from other countries should also be accepted in other countries without the need for a correction or reorganization.

(ii) Multinational Companies: With the development of globalization and foreign trade, multinational companies operate in many countries. With international accounting harmonization, it will be possible to reduce costs in the preparation and consolidation of financial statements of multinational companies, to apply management information systems, to evaluate the performance of international activities and to facilitate personnel movements among the countries in which they operate.

(iii) Independent Audit Firms: The internationalization of capital markets and multinational firms led to the emergence of independent auditing firms operating internationally. International accounting harmonization will facilitate auditing of multinational companies of independent auditing companies, expenses for staff training will be reduced and staff transfers between branches in various countries will be facilitated.

(iv) Economic Associations: In various regions of the world, countries are working to achieve economic integration, and are structured in the form of economic cooperation, economic community and unions. With the international accounting harmonization, it will be ensured that the financial statements regarding the companies operating in the member countries of the union are comparable.

The Turkish Public Oversight Accounting and Auditing Standards Board (KGK) was established on September 26, 2011 and the KGK was authorized in the studies related to accounting standards.

In addition to its efforts to publish and revise the IFRS translated by older Turkish Accounting Standarts Board, KGK issued a draft text in 2015 for the preparation of a local financial reporting set fully compatible with the EU Accounting Directive 2013/34. It entered into force in 2015 in the UK and Ireland and FRS 102 called the local financial reporting kit also contains reference to prepared for companies subject to independent audit in Turkey "Local Financial Reporting Framework" text has been revised in line with public opinion.

As a result, it was published in the Official Gazette numbered 30138 on 29 July 2017 and entered into force as of 2018 by the name of BOBI FRS (Turkish SME FRS Financial Reporting Standard for Large and 
Medium Enterprises). Although the recently implemented SME FRS set is fully compatible with European Union directives such as the TFRS set, there are significant differences in measurement, accounting and reporting between the two sets.

In this study, the effects of the said significant differences between the two sets on the financial reports were examined. For this purpose, inclusive examples were designed and thus, the common financial reporting language of the financial reports prepared according to Turkish Financial Reporting Standarts (TFRS) and Turkish SME FRS sets

It is thought that the study will contribute to the literature in terms of examining the possible effects of application differences on financial reporting by dealing with the different applications between the two sets.

The main purpose of the BOBI FRS is to ensure the unity of practice in the financial reporting and independent audit processes of enterprises that have the feature of being a large and medium-sized enterprise, which are stated in the relevant communiqué, are subject to independent auditing but do not apply TFRS.

Keywords: Turkish Tax Procedure Law, TFRS, BOBI FRS, Financial Statements

Öz: Finansal raporlama için standartlaştırma çalışmaları son yıllarda küresel düzeyde büyük önem kazanmaya başlamıştır. KGK tarafından son olarak yayınlanan "Büyük ve Orta Boy İşletmeler İçin Finansal Raporlama Standardı (BOBİ FRS) Hakkında Tebliğ" ve BOBİ FRS'nin, bağımsız denetime tabi ancak, TMS/TFRS uygulamayacak işletmelerin, münferit ve konsolide finansal tablolarının hazırlanmasında uygulanması zorunlu hale getirilmiştir. Ayrıca Türkiye'de faaliyet gösteren tüm işletmelerin, finansal tablolarını Vergi Usul Kanunu (VUK) hükümlerine göre hazırlamak zorunda olduğu da bilinmektedir. Türkiye'de bağımsız denetime tabi şirketler, VUK'a göre düzenledikleri finansal tabloları daha sonra isteğe bağlı olarak, TFRS'ye yada BOBİ FRS'ye göre çevrim işlemlerine tabi tutarak finansal tablo kalemlerini TFRS'ye yada BOBİ FRS'ye göre yeniden sınıflandırmalıdır. İşte bu noktada çevrim işlemlerine ilişkin muhasebe kayıtları denetçinin çalışma kağıtları üzerinden yapılmakta, muhasebe bilgi sistemine konu edilmemektedir. Bu amaçla çalışmada, bağımsız denetime tabi bir şirketin, VUK'a göre hazırlanmış finansal tabloları ile, isteğe bağlı BOBİ FRS veya TFRS çevrim işlemleri sonucunda oluşan finansal tabloları arasındaki farklar ile ilgili işlemlere ilişkin açıklamaların, finansal tablolara ait dipnotlarda belirtilmemesinden kaynaklanan, VUK, BOBİ FRS ve TFRS ye göre düzenlenmiş finansal tablo farklarının gösterilmesine yönelik bir uygulamaya yer verilmiştir. Çalışmada yer verilen uygulamada, VUK'a göre düzenlenmiş finansal tablolar ile BOBİ FRS veya TFRS'ye göre düzenlenmiş finansal tablolar arasındaki farkların gösterilmesi amaçlanmıştır.

Anahtar Kelimeler: Vergi Usul Kanunu, TFRS, BOBİ FRS, Finansal Tablolar

\section{Giriş}

Sermayenin küresel çapta hareket kabiliyeti kazanması ve ulusal şirketlerin çok uluslu şirketler statüsüne dönüşmesi ile birlikte, uluslararası muhasebe uygulamaları açısından ortak bir dil kullanımı önem kazanmaya başlamıştır (Burton, 2012: 35, 36).

$\mathrm{Bu}$ aşamada muhasebenin temel kavramları ve genel kabul görmüş muhasebe ilkeleri doğrultusunda uluslararası muhasebe standartları oluşturulmuştur. Muhasebe standardı, muhasebe süreçlerini yönlendiren ve finansal tabloların hazırlamasına yön veren normlar şeklinde tanımlanabilmektedir (Ataman ve Akay, 2004: 4). Yazıcı'nın (2003) tanımına göre muhasebe standardı ise; farklı muhasebe sistemlerini uygulayan ülkelerde, dönem sonu hazırlanan finansal tablolarının değerleme ve sunuşlarında ortak bir sunumunun gerçekleşmesi amacıyla uygulanması gereken yazılı kurallar bütünüdür.

Dünya'da muhasebe standartlarına yönelik çalışmalar, 1960 öncesine kadar her ülke tarafından bireysel olarak yapılmaya çalışılmışsa da, bu tarihten sonra belirli ülkelerin işbirliği ile ortak çalışmalar yapılmaya başlanmıştır. Bu çalışmaların sonucunda, 1973 yılında Uluslararası Muhasebe Standartları Komitesi (IASC) oluşturulmuştur. Uluslararası Muhasebe Standartları 
Komitesi, 2001 y1lında Uluslararas1 Muhasebe Standartları Kurulu (IASB) olarak yeniden organize edilmiştir (Alataş ve Kılıç, 2018, s: 455). Bu gelişmenin ardından, 2001 yılına kadar yayınlanmış standartlar IAS kodu ile Uluslararası Muhasebe Standartları olarak kalırken; 2001 yılından sonra IASB'nin yayınlayacağı uluslararası muhasebe standartlarının ise, IFRS kodu ile Uluslararası Finansal Raporlama Standartları olarak yayınlanmasına karar verilmiştir.

Türkiye'de ise ilk olarak TÜRMOB tarafından 1994 yılında, Türkiye Muhasebe ve Denetim Standartları Kurulu (TMUDESK), ulusal muhasebe standartları ile ulusal denetim standartların1 yayınlamak amacıyla kurulmuştur (Gökçen vd, 2011:9). Ardından 1999 yılında, Türkiye Muhasebe Standartları Kurulu (TMSK) oluşturulmuş ve TMUDESK'in yerine 2002 yılında faaliyete başlamıştır(Alataş ve Kılıç, 2018, s: 457-458).

01.01.2005 tarihinden itibaren Sermaye Piyasas1 Kurulu'na (SPK) tabi a tabi olan tüm şirketlerde, 31.12.2006 tarihinde Bankacıl1k Düzenleme ve Denetleme Kurulu'na (BDDK) tabi tüm bankalarda ve 31.12.2008 tarihinden itibaren Hazine Müsteşarlığı'na bağlı tüm sigorta şirketlerinde bağımsız denetime tabi olup olmamasına bakılmaksızın UFRS'ye göre finansal tabloların hazırlanma zorunluluğu ile bunların dışında kalan işletmelerin yurt dışı entegrasyonları çerçevesinde UFRS'ye göre finansal tabloların hazırlanma ihtiyaçlarının günden güne artması ülkemizde UFRS ‘ye uygun finansal tablolarının hazırlanmasını günden güne artırmıştır.

02.11.2011 tarihli 660 sayılı Kanun Hükmünde Kararname (KHK) ile birlikte, TMSK yerine Kamu Gözetimi, Muhasebe ve Denetim Standartları Kurumu (KGK) kurulmuştur. KGK halen Türkiye'de muhasebe standartları yayımlamaya yetkili tek kurum olarak faaliyet göstermektedir.

KGK'nın21/08/2014 tarihli kararında, TFRS uygulama kapsamını, bağımsız denetim kapsamından çıartılarak, genel olarak kamu yararını ilgilendiren kuruluşlarla (KAYİK)sınırlı tutmuştur. TFRS uygulama kapsamı dışında kalan işletmelerin ise, KGK tarafindan yeni bir düzenleme yayımlanıncaya kadar mevcut yürürlükteki mevzuatı uygulamalarına, başka bir ifade ile, Muhasebe Sistemi Uygulama Genel Tebliğleri'ne (MSUGT) tabi olduğuna karar verilmiştir. Daha sonra ise, yine KGK'nın Kurul Kararıyla (sy. 41) “TMS'leri Uygulamayan Şirketlerin Finansal Tablolarının Hazırlanmasında Uygulanacak Illave Hususlar" yayımlanmıştır. Başka bir ifade ile, bağımsız denetime tabi olup, TFRS uygulamayan işletmeler ek ilaveler ile MSUGT'u uygulamaya devam edeceklerdir.

Ancak 01/01/2018'den sonra, bağımsız denetime tabi olan işletmelerin, KGK tarafindan 29/07/2017 tarihinde yayınlanmış olan "Büyük ve Orta Boy İşletmeler İçin Finansal Raporlama Standardı Hakkında Tebliğ" ve eki "Büyük ve Orta Boy İşletmeler İçin Finansal Raporlama Standardı" (BOBİ FRS) ile birlikte BOBİ FRS'yi kullanmaları zorunlu hale getirilmiş̧ir. Başka bir ifadeyle, bağımsız denetime tabi olup, TFRS'yi uygulamayan işletmelerin finansal tablolarının gerçeğe uygun ve karşılaştırılabilir bilgi sağlaması amacıyla, BOBİ FRS'ye uygun olarak hazırlaması zorunlu hale getirilmiştir.

Bu tebliğde TFRS, bazı muafiyetler ile özet 27 bölüm ve 9 ek olarak yer almış ve bütün standartlar tek tebliğde toplanmıştır. UFRS ve $\mathrm{AB}$ düzenlemeleriyle büyük ölçüde uyumlu olan BOBİ FRS'de, $\mathrm{AB}$ düzenlemelerinin küçükleri koru ilkesine uygun olarak, orta boy işletmeler için maliyet esaslı bir raporlama temeli oluşturulmuş iken; büyük boy işletmelere yönelik ise ilave yükümlülükler getirilmiştir (Gücenme, 2017: 2). BOBİ FRS ile TMS/TFRS uyum düzeyi tablo 1'de gösterilmiştir. 


\begin{tabular}{|c|l|c|}
\hline \multicolumn{2}{|c|}{ Tablo 1: BOBİ FRS ve TMS/TFRS Uyumluluk Düzeyi } \\
\hline $\begin{array}{c}\text { Benzerlik } \\
\text { Düzeyi }\end{array}$ & BOBİ FRS Bölümler (B) & $\begin{array}{c}\text { Bölüm } \\
\text { Sayısı }\end{array}$ \\
\hline Yüksek & B2, B3, B4, B7, B8, B10, B11, B13, B15, B16, B17, B18, B20, B23, B24, B27 & 17 \\
\hline Orta & B1, B6, B9, B12, B14, B19, B21, B22, B25 & 9 \\
\hline Düşük & B26 & 1 \\
\hline
\end{tabular}

Kaynakça: Ataman, Çavlak (2017: 165).

$\mathrm{Bu}$ gelişmeleri takiben KGK tarafindan son olarak; bilanço esasına göre defter tutma ölçütlerini sağlayan ancak bağımsız denetim kapsamında olmayan işletmelerin finansal tablolarının, gerçeğe uygun, ihtiyaca uygun ve karşılaştırılabilir olarak sunulması amacıyla, Küęük ve Mikro İşletmeler İçin Finansal Raporlama Standartlarının (KÜMİ FRS) oluşturulmasına karar verilmiş ve 12/07/2019 tarihinde KÜMI FRS Taslak Metnini, kamuoyunun görüşlerine açılacak şekilde yayınlanmıştır (www.kgk.gov.tr).

BOBİ FRS ve KÜMİ FRS ile birlikte; bağımsız denetime tabi olup isteğe bağlı UFRS kullanmayan işletmelerin BOBİ FRS, bağımsız denetime tabi olmayan işletmelerin ise, 2021 yılından itibaren KÜMİ FRS kullanması gerekliliği vurgulanmaktadır (www.kgk.gov.tr). V.U.K.'na göre defter tutulması zorunluluğunun yanında, TMS/TFRS, BOBİ FRS ve uygulamaya başlandığında KÜMİ FRS ile birlikte dört ayrı muhasebe uygulaması ile karşılaşılacağ 1 sonucu ortadadir.

Bu çalışmanın amacı, V.U.K. değerleme ölçülerine göre düzenlenen finansal tablolar ile, UFRS ve BOBİ FRS'ye göre düzenlenen finansal tablolar arasındaki çevrim işlemlerine ilişkin açıklamalarının finansal tablolara ait dipnotlarda belirtilmemesinden kaynaklanan, VUK, UFRS ve BOBİ FRS'ye göre düzenlenmiş finansal tablo farklarının tam olarak irdelenememesidir. Bu amaçla çalışmada, bağımsız denetime tabi seçilmiş bir işletmenin, VUK'na göre düzenlenmiş finansal tabloları ile bağımsız denetimden geçmiş, UFRS ve BOBİ FRS'ye göre çevrim işlemleri ve sinıflandırma kayıtları yapıldıktan sonra oluşan finansal tablolar arasındaki farkların, analiz edilmesine yönelik bir örnek uygulamaya yer verilmiştir.

\section{Literatür Taraması}

Literatüre bakıldığında, tek bir standart veya spesifik bir konu üzerinden TMS/TFRS, BOBİ FRS ve VUK karşılaştırmasına yer veren bir çok çalışma mevcut iken, bu literatür çalışmasında; TMS/TFRS, BOBİ FRS ile MSUGT/VUK hükümleri ile şekillendirilmiş finansal tablolara ilişkin farkların karşılaştırılmasına ve analizine yönelik çalışmalara yer verilecektir. Literatür taraması sonucu elde edilen çalışmalara aşağıda tarih sırası ile yer verilmektedir.

Ataman ve Çavlak (2017) çalışmalarında, BOBİ FRS ile TMS/TFRS karşılaştırmasına yer vermiş̧tir. Çalışmada, iki düzenlemenin büyük ölçüde benzer olduğu, ancak bazı temel noktalarda farklılıkların bulunduğu sonucuna ulaşılmıştır. Ayrıca gerçekleştiren BOBİ FRS'nin içerik analizinde, büyük boy işletmeler ile ve orta boy işletmeler açısından da uygulama farklılıklarının bulunduğu sonucuna ulaşılmıştır.

Doğan (2017) çalışmasında, BOBİ FRS ile TFRS karşılaştırmasına yer vermiştir. Çalışmada; BOBIFRS'nin TFRS ile karşılaştırıldığında, genel olarak benzer olmakla birlikte, BOBİ FRS'nin daha sadeleştirilmiş uygulamalar içerdiği sonucuna ulaşılmıştır.

Ataman, Gökçen ve Çavlak (2018) çalışmalarında, MSUGT göre hazırlanan finansal tabloları ilk olarak BOBİ FRS'ye göre çevrim işlemlerine tabi tutmuş ve BOBİ FRS'ye göre hazırlanan finansal tabloların rasyo yöntemi ile analizine yer vermişlerdir. Çalışmada; MSUGT’ne 
göre hazırlanan temel finansal tablolar ile BOBİ FRS'ye uygun hale getirilmiş finansal tablolar rasyo analizine tabi tutularak karşılaştırılmıştır. Karşılaştırma sonucunda; BOBİFRS'ye göre işletme karlarının azaldığını, rasyoların arasında büyük farklar olduğunu, geleneksel olarak uygulanan rasyoların güncellenmesi gerektiği sonucuna ulaşılmıştır.

Gökçen, Öztürk ve Güleç (2018) çalışmalarında, BOBİ FRS ve TFRS'nin finansal tablolar üzerindeki etkilerini araştırmışlardır. Çalışma sonucunda, BOBİ FRS'ye göre düzenlenen finansal tabloların gerçeğe uygun nitelikte finansal bilgi sunmaktan uzak olduğu yönünde bulgular elde etmişlerdir.

Alataş ve Kılıç (2018) çalışmalarında, BOBİ FRS ve TMS/TFRS arasındaki farkları özet tablolar ile karşılaştırmıştır. Çalışmada iki düzenleme arasında farklılıklar mevcut olsa da, genel olarak düzenlemelerin birbiri ile uyumlu oldukları sonucuna ulaşmışlardır.

Şen ve Özbirecikli (2018) çalışmalarında, BOBİ FRS'nin muhasebe uygulamalarına getirdiği değişiklikleri araştırmıştır. Çalışmada, BOBİ FRS'nin, UFRS uygulamaları ve AB düzenlemeleri ile büyük oranda uyumlu olduğu sonucuna ulaşmışlardır.

Doğan (2018) çalışmasında, BOBİ FRS ile VUK/MSUGT karşılaştırmasına yer vermiştir. Çalışmada; BOBİ FRS'nin, bir finansal raporlama çerçevesinin gerektirdiği tüm özelliklere sahip olduğunu; buna karşılık VUK/MSUGT'a göre düzenlenen finansal tabloların, gerçeğe uygun sunum ve ihtiyaca uygun karşılaştırılabilir bilgi sağlama amacından uzak olduğu sonucuna ulaşılmıştır.

Gökçen, Öztürk ve Güleç (2019) çalışmalarında, KÜMİ FRS Taslağı, BOBİ FRS ve TMS/TFRS'yi temel konular açısından karşılaştırmıştır. Karşılaştırma sonucunda, KÜMİ FRS'nin daha sade ve anlaşılır bir raporlama anlayışı benimsediği, ölçüm ve kaydetme noktasında kolaylaştırıcı uygulamalar içermesi açısından, muhasebe standartlarına geçiş sürecine olumlu katkı sağlayacağ 1 görüşüne ulaşılmıştır.

Otlu ve Güdelci (2019) çalışmalarında, BOBİ FRS'nin muhtemel etkilerini teorik boyutta değerlendirmiştir. Çalışmada, BOBİ FRS'nin kullanımına engel faktörleri ortadan kaldırmak için yapılması gerekenlere ilişkin tavsiyelere yer vermişlerdir.

Karaömer ve Özbirecikli (2019) çalışmalarında, BOBİ FRS ve MSUGT arasındaki farklılıkların finansal tablolar analizi üzerindeki etkilerini araştırmışlardır. İki farklı düzenlemeye göre yapılan analizler sonucunda, düzenlemeler arasında önemli derecede farklılıklar bulunduğunu, BOBİ FRS ve MSUGT/VUK arasındaki farklılıkların büyük ölçüde finansal yapıyla ilgili oranları etkilediği sonucuna ulaşmışlardır.

Gücenme (2020) çalışmasında, KÜMİ FRS taslağını, BOBIFFRS ve vergi uygulamalarımız ile karşılaştırmıştır. Çalışmada, KÜMİ FRS ile BOBİ FRS ve VUK uygulamalarındaki benzerlik ve farklılıklara ilişkin açıklamalara yer verilmiştir. Çalışmanın sonucu olarak KÜMİ FRS'nin, ülkemizde vergi muhasebesi anlayışından ticari muhasebe anlayışına geçilmesinde önemli bir gelişme olduğu sonucuna ulaşmıştır.

Demir (2020) çalışmasında, vergi mizanından BOBİ FRS'ye dönüşüm kayıtlarına ve finansal tabloların oluşturulma sürecine ilişkin bütünsel bir uygulamaya yer vermiştir. Örnek bir uygulama ile standartlarının gereği olan finansal tabloların, vergi mizanı çıkarıldıktan sonra örnek uygulamada olduğu gibi ilave bilgilerin sağlanmasıyla suretiyle düzenlenebileceği sunulmak istenmiştir.

Şen ve Özbirecikli (2020) çalışmalarında, “KÜMİ FRS'nin muhasebe uygulamalarına sağlayabileceği yararları, BOBİ FRS, TMS/TFRS ve MSUGT ile karşılaştırmalı olarak incelemiştir. Çalışmanın sonucunda, KÜMİ FRS genellikle maliyet esaslı bir yaklaşım benimsediği, bu özelliği ile TMS/TFRS ve BOBİ FRS ile karşılaştırıldığında, işletmeler için daha düşük maliyetli olacağ KÜMİ FRS'nin MSUGT'un eksik yanlarını tamamlayıcı uygulamaları içerdiğini, standardın 
uygulanması ile birlikte küçük ve mikro büyüklükte işletmelerin finansal tabloları hem gerçeğe ve ihtiyaca uygun, hem de karşılaştırılabilir olarak sunabileceğini ve KÜMİ FRS'nin, vergi odaklı muhasebeden, bilgilendirme odaklı muhasebe anlayışına geçilmesinde önemli bir rol oynayacağ görüşlerine ulaş1lmıştır.

\section{Uygulama}

Örnek uygulamada, KGK tarafından belirlenmiş hadlere göre bağımsız denetime tabi, halka kapalı ve faaliyet konusunun üretimi ve toptan satışı olan bir şirketin, V.U.K.'na göre hazırlanmış finansal tabloları ile, TMS-TFRS'ye çevrim işlemleri tamamlanmış ve bağımsız denetimden geçmiş TFRS finansal tablolarının karşılaștırılmasına yer verilmiştir. Ayrıca, V.U.K.'na göre hazırlanan finansal tablolar ile TFRS'ye çevrilmiş finansal tablolar arasındaki farkların gösterilmesine ve yine V.U.K.'na göre hazırlanan finansal tabloların, BOBI FRS'ye göre çevrim kayıtlarına yer verilmiş ve nihayetinde VUK - TFRS ve BOBI FRS'ye göre oluşan finansal tabloları arasındaki farkların ortaya konması amaçlanmıştır. Uygulamada KÜMİ FRS henüz taslak halinde yayınlandığından dolayı uygulamaya dahil edilmemiştir.

Uygulamada ilk hareket noktası olarak, V.U.K'a göre hazırlanmış Bilanço ve Gelir Tablosundan hareket edilmiştir.

Ardından V.U.K.'a göre işletme yönetimi tarafından hazırlan finansal tabloların, TFRS ve BOBİ FRS'ye çevrim kayıtlarına yer verilmiştir. Çevrim işlemlerine ilişkin ilk olarak, bir önceki yıl verilen TFRS düzeltme kayıtlarının etkilerinin ters kayıt yapılması suretiyle giderilmesi amaçlı açıllı̧ kaydına yer verilmiştir.

Söz konusu düzeltme kayıtlarının ardından TFRS ve BOBİ FRS'ye dönüştürülmüş finansal tablolara ulaşılmıştır. Sonuç olarak V.U.K.'na göre hazırlanmış finansal tablolar ile TFRS ve BOBİ FRS'ye göre çevrim işlemi tamamlanmış finansal tablolar karşılaştırmalı olarak incelenmiş, benzerlik ve farklara ilişkin yorumlara yer verilmiştir. 


\begin{tabular}{|c|c|c|c|}
\hline \multicolumn{4}{|c|}{ XXX İŞLETMESI 31.12.2018 TARIHLİ V.U.K. BILLANÇOSU } \\
\hline DÖNEN VARLIKLAR & & KISA VADELİ YÜKÜMLÜLÜKLER & \\
\hline Nakit ve Nakit Benzerleri & $4.557 .681,98$ & Finansal Yükümlülükler & 15.053.901,61 \\
\hline Ticari Alacaklar & $20.270 .904,64$ & İlişkili Taraflara Ticari Borçlar & $47.662,73$ \\
\hline İlişkili Taraflardan Alacaklar & $2.355 .508,76$ & Ticari Borçlar & $10.698 .896,41$ \\
\hline Diğer Alacaklar & $16.515,36$ & $\begin{array}{l}\text { Çalışanlara Sağlanan Faydalar Kapsamında } \\
\text { Karşlıklar }\end{array}$ & 0,00 \\
\hline Stoklar & $67.553 .449,98$ & Diğer Kısa Vadeli Yükümlülükler & $8.146 .491,76$ \\
\hline Diğer Dönen Varlıklar & $2.309 .503,11$ & Kısa Vadeli Yükümlükler Toplamı & $\overline{33.946 .952,51}$ \\
\hline \multirow[t]{2}{*}{ Dönen Varlıklar Toplamı } & $97.063 .563,83$ & & \\
\hline & & UZUN VADELİ YÜKÜMLÜLÜKLER & \\
\hline DURAN VARLIKLAR & & Finansal Yükümlülükler & $27.858 .671,74$ \\
\hline Finansal Yatırımlar & $6.216 .027,15$ & Diğer Uzun Vadeli Yükümlülükler & $233.420,32$ \\
\hline Maddi Duran Varlıklar (Net) & $10.040 .166,72$ & Uzun Vadeli Yükümlükler Toplamı & $28.092 .092,06$ \\
\hline $\begin{array}{l}\text { Maddi Olmayan Duran } \\
\text { Varlıklar (Net) }\end{array}$ & $676.507,11$ & & \\
\hline Diğer Duran Varlıklar & $236.541,52$ & ÖZ KAYNAKLAR & \\
\hline \multirow[t]{6}{*}{ Duran Varlıklar Toplamı } & $17.169 .242,50$ & Ödenmiş Sermaye & $35.000 .000,00$ \\
\hline & & Sermaye Yedekleri & $10.093 .342,42$ \\
\hline & & Kar Yedekleri & $623.770,19$ \\
\hline & & Geçmiş Yıl Karları & $2.975 .005,04$ \\
\hline & & Net Dönem Karı & $3.501 .644,11$ \\
\hline & & Öz kaynaklar Toplamı & $\overline{52.193 .761,76}$ \\
\hline TOPLAM VARLIKLAR & $114.232 .806,33$ & TOPLAM KAYNAKLAR & $114.232 .806,33$ \\
\hline
\end{tabular}

\begin{tabular}{|c|c|}
\hline \multicolumn{2}{|c|}{ XXX İŞLETMESİ 01.01-31.12 Dönemine İlişkin V.U.K. Gelir Tablosu } \\
\hline Satış Hasılat & $103.698 .443,00$ \\
\hline Satışların Maliyeti (-) & $-81.590 .902,61$ \\
\hline BRÜT KAR & $22.107 .540,39$ \\
\hline Faaliyet Giderleri (-) & $-8.600 .399,37$ \\
\hline Esas Faaliyetlerden Diğer Gelir ve Kazançlar & $497.339,59$ \\
\hline Esas Faaliyetlerden Diğer Giderler ve Zararlar (-) & $-864.601,09$ \\
\hline FAALIYET KARI /(ZARARI) & $13.139 .879,52$ \\
\hline Diğer Faaliyetlerinden Gelirler & $213.838,37$ \\
\hline Diğer Faaliyetlerden Giderler (-) & $-231.369,77$ \\
\hline Finansman Giderleri (-) & $-8.567 .802,66$ \\
\hline VERGİ ÖNCESİ KAR & 4.554.545,46 \\
\hline DÖNEM VERGİ YASAL YÜKÜMLÜLÜKLERİ KARŞ (-) & $-1.052 .901,35$ \\
\hline VERGİ SONRASI KAR & $3.501 .644,11$ \\
\hline
\end{tabular}




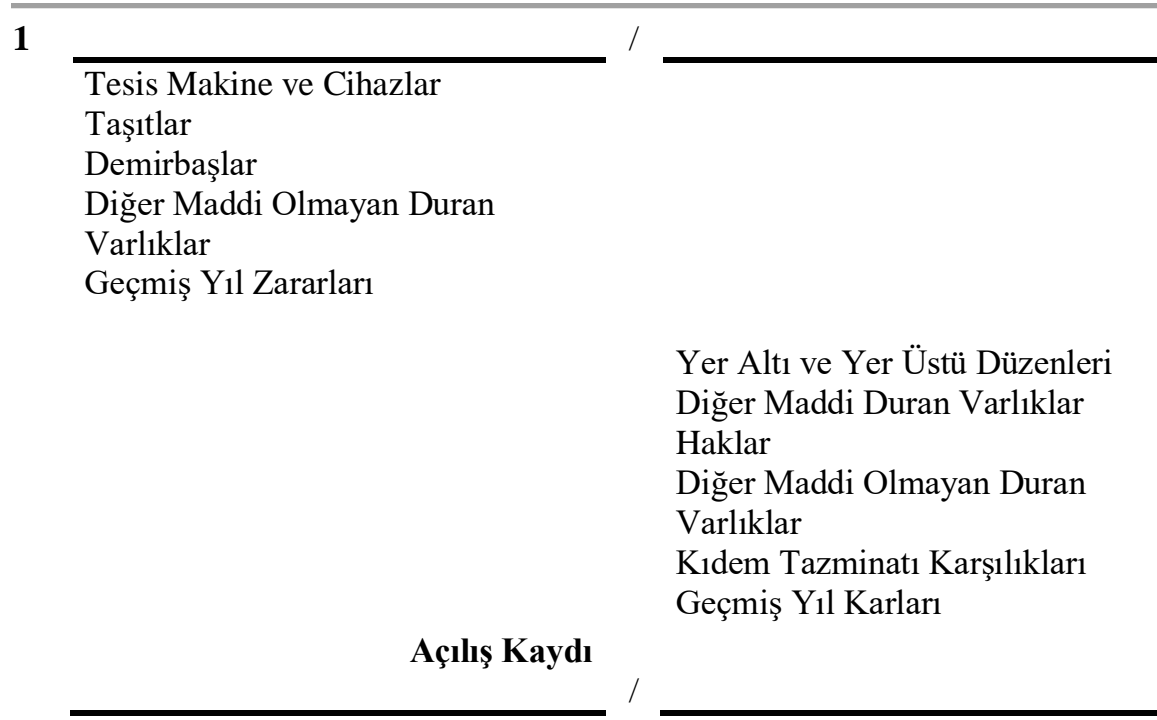

$10.654,29$

$34.030,40$

$9.024,20$

$1.511,54$

$914.107,34$

$11.900,32$

$196.258,81$

$62.304,19$

$17.906,21$

$625.737,81$

$55.220,43$

\section{Düzeltme Kaytlart:}

1) İşletme 2018 y1lında VUK finansal tablolarında maddi duran varlıklarına amortisman ayırmadığı tespit edilmiștir. Oysa ki, TMS 16- Maddi Duran Varlıklar Standardı'na (pr.46) göre; her faaliyet dönemine ilişkin amortisman giderlerinin, ilgili dönemin gelir tablosu ile ilişkilendirilmesi gerektiğine dair ifade yer almaktadır.

Yine aynı şekilde; BOBI FRS Maddi Duran Varlıkları, Bölüm 12’ de (pr.12.21); İşletmelerin sahip oldukları maddi duran varlıklara, ilgili dönemlere ait amortisman ayrılması ve gelir tablosu ile ilişkilendirmesi gerekliliği yer almaktadır. Bu kapsamda, TMS ve BOBI FRS'ye göre düzeltme kaydı aşağıdaki şekilde gerçekleştirilmiştir.

\begin{tabular}{|c|c|}
\hline \multicolumn{2}{|l|}{ Genel Yönetim Giderleri } \\
\hline & Yer Altı ve Yer Üstü Düzenleri \\
\hline & Binalar \\
\hline & Tesis Makine Cihazlar \\
\hline & Taşıtlar \\
\hline & Demirbaşlar \\
\hline & Diğer Maddi Duran Varlıklar \\
\hline \multicolumn{2}{|c|}{ Maddi Duran Varlıklara Amortisman Ayrılması } \\
\hline & \\
\hline
\end{tabular}

$879.574,10$

$11.900,32$

$34.258,52$

$496.359,74$

$140.813,44$

$196.242,08$

2) TMS- 16 - Maddi Duran Varlıklar standardı ve BOBI FRS Bölüm 12- Maddi Duran Varlıklar'a (pr.12.26) göre; Amortisman ayrılmasına, duran varlı̆̆ın kullanıma hazır olduğu dönemde başlanır. Duran varlığın finansal tablo dışı bırakılmasıyla ise amortisman ayrılması işlemi sonlandırılır. Bu sebeple dönem içerisinde kullanıma alınan duran varlıklar için kıst amortisman ayrilmalıdır ifadeleri yer almaktadır.

Bu kapsamda, 2018 yılı içinde alınan maddi duran varlıklara TMS ve BOBI FRS'ye göre ayrılması gereken kıst amortismana ilişkin düzeltme kaydı aşağıdaki şekilde gerçekleştirilmiştir. 


\section{I}

Tesis Makine ve Cihazlar

Taşitlar

$104.706,48$

Demirbaşlar

$26.654,66$

Genel Yönetim Giderleri

Fazla Ayrılan Maddi Duran Varlık Amortismanlarının Düzeltilmesi

$144.918,96$ I

3) TMS 38- Maddi Olmayan Duran Varlıklar Standardı'na (pr.97) göre, sinırlı ömre sahip maddi olmayan duran varlıkların, yararlı ömrü boyunca itfaya tabi tutulması gerekmektedir. İtfa işlemine maddi olmayan duran varlığın hazır olduğu dönemde başlanmalıdır. BOBI FRS Bölüm 14- Maddi Olmayan Duran Varlıklar'a (pr. 14.22) göre, faydalı ömrü sınırlı olan maddi duran varlıkların ilgili dönemde itfaya tabi tutulması zorunludur ifadeleri yer almaktadır.

Bu kapsamında, 2018 yılı içinde elde edilmiş olan maddi olmayan duran varlıkların kıst amortismanına ilişkin yapılması gereken TMS ve BOBİ FRS düzeltme kaydı, aşağıdaki şekilde gerçekleştirilmiştir.

\begin{tabular}{|c|c|c|}
\hline \multirow{3}{*}{ Genel Yönetim Giderleri } & & \\
\hline & Haklar & $62.304,19$ \\
\hline & Diğer Maddi Olmayan Duran Varlıklar & $18.370,88$ \\
\hline
\end{tabular}

Maddi Olmayan Duran Varlıklara Amortisman Ayrilması I

4) TMS- 38 - Maddi Olmayan Duran Varlıklar Standardı ve BOBI FRS Bölüm 14Maddi Olmayan Duran Varlıklar'a (pr.14.25) göre, maddi duran varlıklarda olduğu gibi maddi olmayan duran varlıklar içinde, dönem içerisinde kullanıma alınan maddi olmayan duran varlıklar için kıst amortisman ayrılmalıdır ifadeleri yer almaktadır.

$\mathrm{Bu}$ kapsamda, TMS ve BOBI FRS'ye göre düzeltme kaydı aşağıdaki şekilde gerçekleştirilmiştir.

Diğer Maddi Olmayan Duran Varlıklar
Genel Yönetim Giderleri

Fazla Ayrılan Maddi Olmayan Duran Varlık Amortismanların Düzeltilmesi<smiles>[CH]C</smiles>

5) TFRS 9- Finansal Araçlar Standardı'na (B.5. pr.5.33) göre, sabit maliyetli borçlanmalar için etkin faiz yöntemi uygulanmaktadır. Etkin faiz yöntemi, bu standart temelli oluşumlarda; finansal varlık veya borcun (veya bir finansal varlık veya borç grubunun) itfa edilmiş maliyetlerinin hesaplanması ve ilgili faiz gelir veya giderlerinin ilişkili olduğu döneme dağıtılmasında kullanılan bir yöntemdir. Uygulamanın temeli gelecekteki değer veya bugünkü değer hesaplamasının basit faiz esasına göre değil, "bileşik faiz esasına göre” yapılıyor olmasıdır. 
Borçlanma için düşünüldüğünde ise, etkin faiz oranı borçlanma anında ile değerleme tarihinde borçlanma maliyetini belirleyen faiz oranıdır. Değerleme tarihinde bu yöntem kullanılarak bulunan değer reeskont değeri olup "iskonto edilmiş değer", "itfa edilmiş maliyet değeri" veya "bugünkü değer" de denilmektedir.

Bu açıklamalara göre, hem TFRS-9 hem de BOBI FRS ile ilgili, aynı anda bu hususla alakalı aynı düzeltme kaydı kayıtlara alınmıştır.

\begin{tabular}{l}
$\begin{array}{l}\text { Finansman Giderleri } \\
\text { Finansal Yükümlülükler }\end{array}$ \\
\begin{tabular}{l} 
Etkin Faiz Yöntemiyle Hesaplanan Banka Kredi Faiz Kaydı \\
\hline
\end{tabular} \\
\hline
\end{tabular}

6) TMS-19 Çalışanlara Sağlanan Faydalar Standardı'na (pr.67) göre, fayda yükümlüklerinin bugünkü değere indirgenmiş değerlerin hesaplanması yöntemi kabul görmekte, cari dönemde hizmet maliyetlerinin ve işçilik maliyetlerinin belirlemesinde bu yöntem kullanmaktadır. Ayrıca BOBİ FRS Bölüm 19'da (pr.19.17.) ise; "Cari dönemde ortaya çıkan kıdem tazminatı yükümlülük artışları hesaplanarak giderleştirilmelidir" hükmü yer almaktadır. Bu açıklamalara göre, TMS - 19 ve BOBI FRS Bölüm 19'a göre yapılası gereken düzeltme kaydı aşağıdaki gibidir.

\section{Kıdem Tazminatı Karşılı̆ı Ayrılması}<smiles>[3H]</smiles>

7) TFRS-9 Finansal Araçlar Standard'’na (pr. 5.5.15. ii bendi) göre, işletmeler muhasebe politikası olarak zarar karşı1ıklarını, kredi zararlarına eşit bir tutarda ölçmesi durumunda bu husus, TFRS 15 - Sözleşmelerden Hasılat Standardı'na göre önemli bir finansman bileşeni içerir ve bu politika TFRS-15'e göre sözleşme varlıklarının tamamına uygulanır. BOBI FRS Bölüm 9 Finansal Araçlar ve Özkaynaklar'da (pr.10) ise; işletme dönem sonlarında tahsili şüpheli hale gelen şüpheli alacaklarını tahmin etmeli ve bunlar için değer düşüklüğü (şüpheli alacak karşılığı) hesaplaması hükmü bulunmaktadır.

Bu kapsamda, TFRS-9 ve BOBI FRS'ye göre aşağıdaki düzeltme kayıtları verilmiştir. I

Karşlık Giderleri $122.478,50$

Şüpheli Tic. Alacaklar Karş.

Şüpheli Ticari Alacaklara Karşılık Ayrılması

$122.478,50$ I

8) TFRS 9- Finansal Araçlar Standardı'na (pr.5.5.35) göre, işletme ticari alacaklarında 12 aylık beklenen kredi zararlarını tahmin etmek amacı ile, bu finansal varlıklara ilişkin geçmiş kredi zarar deneyimlerinden faydalanacak ve kredi zararlarını uygun faiz oranı ile finansal durum tablosu gününe uygun faiz oranı ile indirgeyecektir. 
BOBI FRS Bölüm 9- Finansal Araçlar ve Özkaynaklar'da (pr.8), bir y1ldan uzun süreli alacaklar ve borçlar itfa edilmiş değeri üzerinden ölçülmekte hükmü yer almaktadır. Bu kapsamda, uygulamada şirketin alacakları 1 yıldan kısa sürede olduğu için, sadece TFRS mali tablolarda düzeltme işlemi aşağıdaki gibi gösterilmiştir.

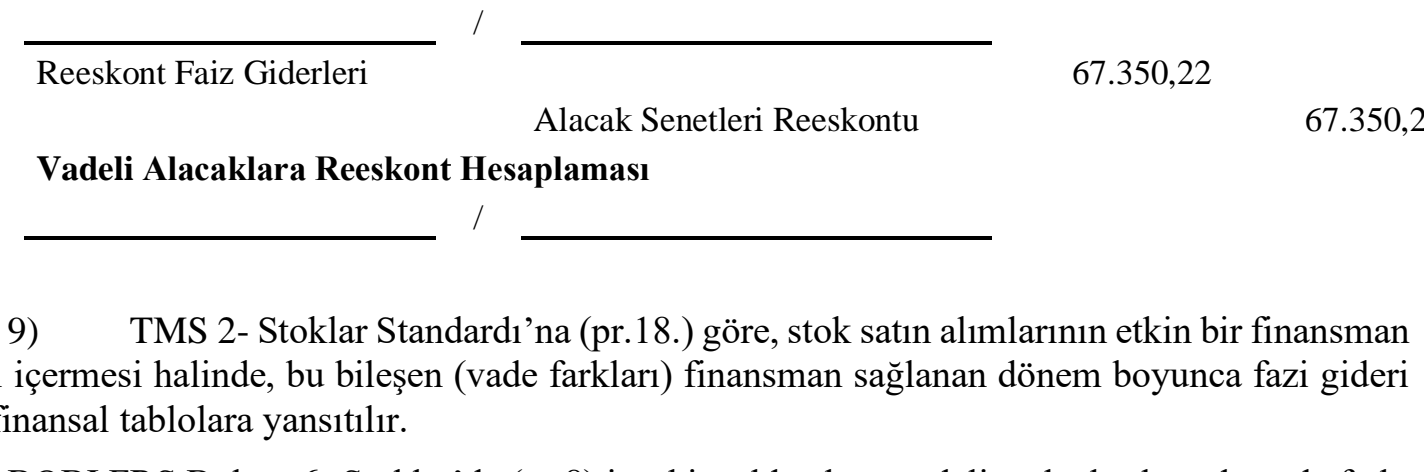

BOBI FRS Bölüm 6- Stoklar'da (pr.8) ise, bir yıldan kısa vadeli stok alımlarında vade fark1 ayrıştırılamayacağı, vadenin bir yıldan uzun sürmesi durumunda vade farklarının etkin faiz yöntemine göre hesaplanarak faiz giderinin muhasebeleştirileceğine yer vermiştir.

Uygulamamızda, ilgili işletmenin faaliyet konusunun un ticareti olması ve stoklarını bir yıldan daha az vade ile satın alması sebebiyle, sadece TFRS'ye göre finansal tablolarda düzeltme yapılmıştır.

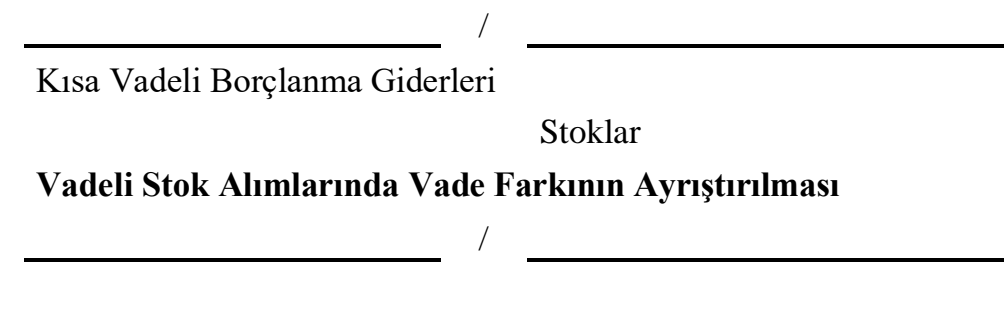

$102.400,00$

$102.400,00$

10) TMS 2 - Stoklar Standardı'na (pr.9) göre stoklar, maliyet değeri ile net gerçekleşebilir değerin düşük olanı üzerinden ölçülü ifadesi yer almaktadır. Yine BOBI FRS Bölüm 6- Stoklar'a (pr.22) göre, her rapor dönemi sonunda stokların değer düşüklüğüne uğrayıp uğramadığ1 değerlendirilir ve aynı şekilde, TMS-2'de olduğu gibi maliyet bedeli ile net defter değeri karşılaştırılarak düşük olanı ile değerlenir. Net gerçekleşebilir değeri stok maliyet bedelinden daha düşük seviyede ise, aradaki fark stok değer düşüklüğü karşıllı̆ı olarak finansal tablolara yansıtılır.

Uygulamamizda hem TFRS finansal tablolarda hem de BOBI FRS finansal tablolarda stokların maliyet bedeli ile net gerçekleşebilir değerleri karşılaştırılmış, stokların net gerçekleşebilir değeri daha düşük olduğu için aradaki fark, stok değer düşük karşılığı olarak kayıtlara yansıtılmıştır.

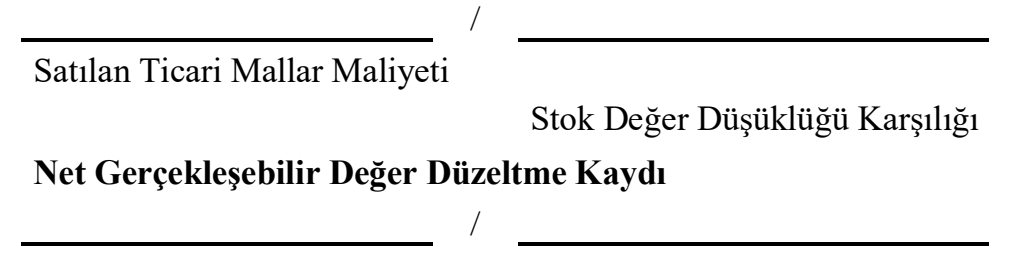

$204.800,75$

$204.800,75$

11) TMS - 16 Maddi Duran Varlıklar Standardı (pr.58), bina satın alındığında arsa payını da içerdiğinden ayrı olarak muhasebeleştirilmesi gereğinden bahseder. Ayrıca aynı standart, arsaların sonsuz faydalı ömre sahip olduğu için amortismana tabi tutulamayacağını, binaların ise, sınırlı faydalı ömre sahip olduklarından amortismana tabi tutulacağını belirtmiştir. 
BOBI FRS Bölüm 12- Maddi Duran Varlıklar (pr. 5) ise, arsa - arazi ile binaların birbirinden ayrılabilir varlıklar olduğunu, beraber edinilseler bile ayrı muhasebeleştirileceğini ifade eder. Yine BOBİ FRS Bölüm 12'ye (pr.23) göre, arsa ve araziler sınırsı faydalı ömre sahip olduklarından amortismana tâbi değildir hükmü yer almaktadır.

Uygulamamızda hem TFRS hem de BOBI FRS finansal tablolarda, hem binanın arsadan aldığı pay düşüldükten sonra arsaya ait amortisman tutarının iptal edilmesi gerekmektedir.

Birikmiş Amortismanlar

Arsa Amortismanı İptali
1

$$
\text { Birikmiş Amortismanlar }
$$

Faaliyet Giderleri
$14.800,00$

$7.400,00$

$7.400,00$

\section{2) Ertelenmiş Vergi Hesaplaması}

Son olarak uygulamamızda, TMS - 12 Gelir Vergileri Standardı'nın ifade ettiği ertelenmiş vergi, işletmemizin finansal tablolarına yansıtılmıştır. Ancak BOBİ FRS Bölüm 23 Gelir Üzerinden Alınan Vergiler Standardın'da, orta boy işletmeler için ertelenmiş vergi hesaplanması zorunluluğu belirtilmediği üzere, uygulamamıza konu işletme orta boy kriterleri taşıdığından dolayı, uygulamada ertelenmiş vergi BOBİ FRS'ye göre hesaplanmamıştır. TMS 12'ye göre, Finansal tablolara yansıtılan düzeltme kayıtlarıyla ilgili ortaya çıkan, cari döneme ait veya sonraki dönemlere ilişkin vergilerin kayda alınması gerekir (Ataman vd, 2018:295).

Uygulamamıza ilişkin ertelenen vergi varlığı ve yükümlülügünün ortaya çıkış nedenleri, TMS/TFRS göre aşağıdaki gibi özetlenebilir:

Tablo 1: TFRS'ye göre Ertelenmis Vergi;

\begin{tabular}{|c|c|c|c|c|}
\hline $\begin{array}{l}\text { Madde } \\
\text { No }\end{array}$ & Ertelenen Vergi Öğesi & $\begin{array}{l}\text { İlgili TMS } \\
\text { - TFRS } \\
\end{array}$ & $\begin{array}{c}\text { Ertelenen Vergi } \\
\text { Varlığ }\end{array}$ & $\begin{array}{l}\text { Ertelenen Vergi } \\
\text { Yükümlülükleri }\end{array}$ \\
\hline 1 & $\begin{array}{c}\text { Maddi duran varlıklara amortisman } \\
\text { ayrilması }\end{array}$ & TMS - 16 & $879.574,10$ & \\
\hline 2 & $\begin{array}{c}\text { Fazla ayrılan maddi duran varlık } \\
\text { amortismanlarının düzeltilmesi }\end{array}$ & TMS - 16 & & $144.918,96$ \\
\hline 3 & $\begin{array}{l}\text { Maddi olmayan duran varlıklara } \\
\text { amortisman ayrılması }\end{array}$ & TMS - 38 & $80.675,07$ & \\
\hline 4 & $\begin{array}{c}\text { Fazla ayrılan maddi olmayan duran varlık } \\
\text { amortismanlarının düzeltilmesi }\end{array}$ & TMS - 38 & & 226,00 \\
\hline 5 & $\begin{array}{c}\text { Etkin faiz yöntemiyle hesaplanan banka } \\
\text { kredi faizleri kaydı }\end{array}$ & TFRS -9 & $4.724 .783,44$ & \\
\hline 6 & Kıdem Tazminatı karşılığı ayrılması & TMS-19 & $132.111,41$ & \\
\hline 7 & Şüpheli ticari alacaklara karşılık ayrılması & TFRS -9 & $122.478,50$ & \\
\hline 8 & Vadeli alacaklara reeskont hesaplaması & TFRS -9 & $67.350,22$ & \\
\hline 9 & $\begin{array}{l}\text { Vadeli stok alımlarında vade farkının } \\
\text { ayrıştırılması }\end{array}$ & TMS - 2 & $102.400,00$ & \\
\hline 10 & Net gerçekleşebilir değer düzeltme kaydı & TMS - 2 & $204.800,75$ & \\
\hline \multirow[t]{2}{*}{11} & Arsa amortismanı İptali & TMS - 16 & & $7.400,00$ \\
\hline & & Toplam & 6.314.173,49 & $152.544,96$ \\
\hline
\end{tabular}


Ertelenen Vergi Varlıkları $=6.314 .173,49 * 0,22=1.389 .118,17$ TL

Ertelenen Vergi Yükümlülükleri $=152.544,96 * 0,22=33.559,89$ TL

$$
\text { I }
$$

Ertelenen Vergi Varlıkları

Ertelenen Vergi

Yükümlülükleri

Dön. Vergi. Yas. Yük. Karşılıkları

$1.355 .558,28$

Ertelenmiş Vergi Düzeltme Kaydı (TFRS)$$
\text { I }
$$ 


\begin{tabular}{|c|c|c|c|}
\hline \multicolumn{4}{|c|}{ XXX İŞLETMESI 31.12.2018 TARİHLİ KARŞILAŞTIRMALI FİNANSAL DURUM TABLOSU } \\
\hline & VUK & TFRS & BOBI FRS \\
\hline \multicolumn{4}{|l|}{ DÖNEN VARLIKLAR } \\
\hline Nakit ve Nakit Benzerleri & $328.222,68$ & $328.222,68$ & $328.222,68$ \\
\hline Ticari Alacaklar & $20.270 .904,64$ & $21.617 .026,42$ & $21.720 .680,77$ \\
\hline İlişkili Taraflardan Alacaklar & $2.355 .508,76$ & $2.355 .508,76$ & $2.355 .508,76$ \\
\hline Diğer Alacaklar & $16.515,36$ & $19.673,74$ & $19.673,74$ \\
\hline Stoklar & $67.553 .449,98$ & $67.246 .249,23$ & $67.348 .649,23$ \\
\hline Diğer Dönen Varlıklar & $2.309 .503,11$ & $2.309 .503,11$ & $2.309 .503,11$ \\
\hline Ertelenmiş Vergi Varlıkları & 0,00 & $1.389 .118,17$ & 0,00 \\
\hline Dönen Varlıklar Toplamı & $92.834 .104,53$ & $95.265 .302,11$ & $94.082 .238,29$ \\
\hline \multicolumn{4}{|l|}{ DURAN VARLIKLAR } \\
\hline Finansal Yatırımlar & $6.216 .027,15$ & $6.216 .027,15$ & $6.216 .027,15$ \\
\hline Maddi Duran Varlıklar (Net) & $10.040 .166,72$ & $9.158 .461,34$ & $9.143 .661,34$ \\
\hline $\begin{array}{l}\text { Maddi Olmayan Duran Varlıklar } \\
\text { (Net) }\end{array}$ & $676.507,11$ & $517.359,18$ & $517.359,18$ \\
\hline \multirow{2}{*}{$\begin{array}{l}\text { Diğer Duran Varlıklar } \\
\text { Duran Varlıklar Toplamı }\end{array}$} & $236.541,52$ & $236.541,52$ & $236.541,52$ \\
\hline & $\overline{17.169 .242,50}$ & $\overline{16.128 .389,19}$ & $16.113 .589,19$ \\
\hline TOPLAM VARLIKLAR & $\overline{110.003 .347,03}$ & $111.393 .691,30$ & $110.195 .827,48$ \\
\hline \multicolumn{4}{|l|}{ KISA VADELİ } \\
\hline \multicolumn{4}{|l|}{ YÜKÜMLÜLÜKLER } \\
\hline Finansal Yükümlülükler & $15.053 .901,61$ & $33.399 .202,64$ & 33.399.202,64 \\
\hline İlişkili Taraflara Ticari Borçlar & $47.662,73$ & $47.662,73$ & $47.662,73$ \\
\hline Ticari Borçlar & $10.698 .896,41$ & $10.698 .896,41$ & $10.698 .896,41$ \\
\hline Diğer Kısa Vadeli Yükümlülükler & $8.146 .491,76$ & $8.167 .257,91$ & $8.167 .257,91$ \\
\hline Ertelenmiş Vergi Yükümlükleri & 0,00 & $33.559,89$ & 0,00 \\
\hline \multirow{2}{*}{ Kısa Vadeli Yükümlükler } & $33.946 .952,51$ & $52.346 .579,58$ & 52.313.019,69 \\
\hline & & & \\
\hline \multirow{2}{*}{\multicolumn{4}{|c|}{$\begin{array}{l}\text { UZUN VADELİ } \\
\text { YÜKÜMLÜLÜKLER }\end{array}$}} \\
\hline & & & \\
\hline Finansal Yükümlülükler & 23.629.212,44 & $14.238 .154,15$ & $14.238 .154,15$ \\
\hline \multirow{2}{*}{\multicolumn{4}{|c|}{ Kapsamında Karș1liklar }} \\
\hline & & & \\
\hline \multicolumn{4}{|l|}{$\begin{array}{l}\text { Diğer Uzun Vadeli } \\
\text { Yükümlülükler }\end{array}$} \\
\hline $\begin{array}{r}\text { Uzun Vadeli Yükümlükler } \\
\text { Toplamı }\end{array}$ & $23.862 .632,76$ & $\overline{15.229 .423,69}$ & $15.229 .423,69$ \\
\hline \multicolumn{4}{|l|}{ ÖZ KAYNAKLAR } \\
\hline Ödenmiş Sermaye & $35.000 .000,00$ & $35.000 .000,00$ & $35.000 .000,00$ \\
\hline Sermaye Yedekleri & $10.093 .342,42$ & $10.022 .009,44$ & $10.022 .009,44$ \\
\hline Kar Yedekleri & $623.770,19$ & $623.770,19$ & $623.770,19$ \\
\hline Geçmiş Yıl Karları & $2.975 .005,04$ & $1.984 .006,72$ & $1.984 .006,72$ \\
\hline Net Dönem Karı & $3.501 .644,11$ & $-3.812 .098,32$ & $-4.976 .402,25$ \\
\hline Öz kaynaklar Toplamı & $\overline{52.193 .761,76}$ & $\overline{43.817 .688,03}$ & $42.653 .384,10$ \\
\hline TOPLAM KAYNAKLAR & $110.003 .347,03$ & $111.393 .691,30$ & $110.195 .827,48$ \\
\hline
\end{tabular}




\begin{tabular}{|c|c|c|c|}
\hline \multicolumn{4}{|c|}{$\begin{array}{l}\text { XXX İŞLETMESİ 01.01.2018-31.12.2018 DÖNEMINNE İLISSKINI KARŞILAŞTIRMALI KAR/ZARAR VE } \\
\text { KAPSAMLI GELIR TABLOSU }\end{array}$} \\
\hline & VUK & TFRS & BOBI FRS \\
\hline Satış Hasılat & $103.698 .443,00$ & $103.698 .443,00$ & $103.698 .443,00$ \\
\hline Satışların Maliyeti (-) & $-81.590 .902,61$ & $-81.795 .703,36$ & $-81.795 .703,36$ \\
\hline BRÜT KAR & 22.107.540,39 & $21.902 .739,64$ & $21.902 .739,64$ \\
\hline Faaliyet Giderleri (-) & $-8.600 .399,37$ & $-9.408 .103,58$ & $-9.422 .903,58$ \\
\hline Esas Faaliyetlerden Diğer Gelir ve Kazançlar & $497.339,59$ & $525.815,17$ & $657.926,31$ \\
\hline Esas Faaliyetlerden Diğer Giderler ve Zararlar (-) & $-864.601,09$ & $-1.037 .868,00$ & $-1.102 .628,92$ \\
\hline FAALIYYET KARI /(ZARARI) & 13.139.879,52 & $11.982 .583,23$ & $12.035 .133,45$ \\
\hline Diğer Faaliyetlerinden Gelirler & $213.838,37$ & $8.764,19$ & $8.764,19$ \\
\hline Diğer Faaliyetlerden Giderler (-) & $-231.369,77$ & 0,00 & 0,00 \\
\hline Finansman Giderleri (-) & $-8.567 .802,66$ & $-13.394 .986,10$ & $-13.292 .586,10$ \\
\hline VERGI ÖNCESİ KAR & 4.554.545,46 & $-1.403 .638,68$ & $-1.248 .688,46$ \\
\hline $\begin{array}{l}\text { DÖNEM VERGİ YASAL } \\
\text { YÜKÜMLÜLÜKLERİ KARŞ (-) }\end{array}$ & $-1.052 .901,35$ & $-2.408 .459,64$ & $-3.727 .713,79$ \\
\hline VERGI SONRASI KAR (ZARAR) & $3.501 .644,11$ & $-3.812 .098,32$ & $-4.976 .402,25$ \\
\hline
\end{tabular}

\subsection{Uygulamanın Bulguları}

Uygulamamız sonucunda, halka kapalı un üretimini ve toptan satışını yapan, bağımsız denetime tabi bir işletmenin V.U.K.'a göre hazırlanan finansal tablolardan, TFRS ve BOBI FRS finansal tablolara geçiş sonucunda Şirket'in; V.U.K. finansal tablolarından - TFRS ve BOBI FRS finansal tablo kalemleri arasındaki artış ve azalışlar aşağıdaki tabloda özet olarak gösterilmiştir (Bin TL):

Tablo 3: V.U.K., TFRS ve BOBİ FRS Dönüşüm Farkları Karşılaştırılması

\begin{tabular}{|l|r|r|r|}
\hline \multicolumn{1}{|c|}{ (Bin TL) } & \multicolumn{1}{c|}{ VUK } & \multicolumn{1}{c|}{ TFRS } & \multicolumn{1}{c|}{ BOBं FRS } \\
\hline Dönen Varlıklar Toplamı & 92.834 & 95.265 & 94.082 \\
\hline Duran Varlıklar Toplamı & 17.169 & 16.128 & 16.113 \\
\hline Kısa Vadeli Yabancı Kaynaklar & 33.947 & 52.347 & 52.313 \\
\hline Uzun Vadeli Yabancı Kaynaklar & 23.863 & 15.229 & 15.229 \\
\hline Öz kaynaklar & 52.194 & 43.818 & 42.653 \\
\hline Dönem Kar (Zarar) & $\mathbf{3 . 5 0 2}$ & $\mathbf{- 3 . 8 1 2}$ & $\mathbf{- 4 . 9 7 6}$ \\
\hline
\end{tabular}

Hesap grupları bazında en büyük artışı düzeltme kayıtları sonrası kısa vadeli yabancı kaynaklar grubunda meydana gediği, uzun vadeli yabancı kaynaklarda ve özkaynaklarda ise önemli düşüsün meydana geldiği gözlemlenmiştir.

V.U.K. - TFRS ve BOBİ FRS finansal tablo kalemleri arasında en önemli değişim, V.U.K. finansal tablolarında 3.502 bin TL dönem karı yer alırken; TFRS ve BOBI FRS finansal tablolarında ciddi bir değişiklik göstererek şirket mali tablolarını zarar olarak raporlanmıştır.

Bu kâr zarar değişikliğinin en önemli nedeni, banka kredilerine ilgili TFRS ve BOBI FRS standartlarına göre etkin faiz hesaplamasının mali tablolara yansıtılmasından kaynaklanmıştır.

\section{Sonuç}

Türkiye'de, VUK'na göre yasal olarak düzenlenmesi zorunlu finansal tabloların, bağımsız denetim faaliyetleri kapsamında, isteğe bağl1 TFRS veya BOBI FRS'ye göre düzenlenmiş finansal 
tablolara geçiş işlemleri açıklanmamakta, sadece çevrim işlemi tamamlanmış ilgili finansal tabloların verilmesi ile yetinilmektedir. Bu da söz konusu dönüşüm sürecinin tam olarak kavranamamasına, yanlış yorumlanmasına ve çevrim sürecinin anlaşılamamasına neden olabilmektedir.

$\mathrm{Bu}$ dönüşüm işlemleri genel olarak bağımsız denetçilerin çalışma kağıtlarında v.b. dokümanlarında gösterilmektedir. Bu sebeple, TFRS ve BOBİ FRS finansal tabloları ve dipnotları okuyan ve yorumlayan bir üçüncü taraf, V.U.K.'na göre hazırlanmış finansal tabloları ve bunların dipnotlarını göremediği için, kar beyan edilen finansal tablolardan zarar raporlanan finansal tablolara veya zarar beyan edilen finansal tablolardan kar raporlanan finansal tablolara geçiş sürecini analiz edememektedirler.

Özellikle V.U.K. finansal tabloları ile TFRS ve BOBI FRS finansal tabloları arasındaki farklar dikkati çeker niteliktedir. Bu farklar standartlara göre yapılması zorunlu, kar zararı etkiyen düzeltme kayıtları ile kar zararı etkilemeyen sınıflandırma kayıtlarından meydana gelmektedir.

Söz konusu bu farkların, özellikle finansal oranlar üzerinde yaratacağı değişim etkisi ve yorum farklılıklarına neden olabileceği açık bir şekilde görülmektedir. Özellikle Banka kredi tahsis birimlerine sunulan farklı standartlara göre hazırlanan ayrı finansal tablolar, kredi talep eden işletmelerin risklerini belirlemede yanlış yorumlara neden olabilmektedir. Bilindiği gibi finansal oranlar sadece finansal yapının analizi ve geleceğe ilişkin işletme hedeflerinin tahmin edilmesi açısından değil, ayrıca işletmelerin kamu ile ilişkileri açısından da önemli bir yere sahiptir. Ülkemizde amir düzenleyici kurum olan Kamu Gözetim Kurumu tarafından yapabilecek bir düzenleme ile, TFRS ve BOBI FRS'ye göre düzenlenen finansal tablo dipnotlarına ilaveler yapılarak, düzeltme ve sınıflandırma kayıtlarının özet olarak sunulması ile birlikte; TFRS ve BOBI FRS'ye göre hazırlanan finansal tabloların daha etkin olarak sunulacağı, bununla birlikte daha kolay analiz edileceği ve bu finansal tablolar ile kullanıcıların daha etkin karar alabilecekleri düşüncesindeyiz.

\section{Kaynakça}

Alataş, A., Kılıç, İ. (2018). "Özet Tablolar ile BOBİ FRS ve TMS/TFRS Arasındaki Farkların Karşılaştırılması”, Akademik Sosyal Araştırmalar Dergisi, Yı1: 6, Sayı: 64, Ocak, 453-478.

Ataman, B., Gökçen, G., Çavlak, H. (2018). "Muhasebe Sistemi Uygulama Genel Tebliği'ne (MSUGT’ye) Göre Hazırlanan Finansal Tabloların Büyük ve Orta Boy İşletmeler için Finansal Raporlama Standardı'na (BOBİ FRS'ye) Uyarlanması ve Rasyo Yöntemi İle Analizi” Finans Ekonomi ve Sosyal Araştırmalar Dergisi, 3(2), 458-477.

Ataman, B., Akay, H. (2004). Uluslararası Muhasebe Standartları ve Türkiye'de Uygunluğuna İlişkin Bir Araştırma, 2. Bask1, Türkmen Kitabevi.

Ataman, B., Çavlak, H.(2017). "Büyük ve Orta Boy İşletmeler için Finansal Raporlama Standardı (BOBİ FRS) ile Tam Set Türkiye Muhasebe ve Türkiye Finansal Raporlama Standartlarının (TMS/TFRS) Karşılaştırılması”, Finans Ekonomi ve Sosyal Araştırmalar Dergisi, Sayı 3, $153-168$.

Burton, F. Greg (2012). "A Cross-Cultural Study of the Influence of Country of Origin, Justice, Power Distance, and Gender on Ethical Decision Making", Journal of International Accounting Research, Cilt: 11, Say1: 1, 35 - 44.

Demir, S. (2020). "Vergi Mizanından BOBİ FRS'ye Dönüşüm Kayıtlarının Yapılması Ve Finansal Tablolar Çıkarılmasına Dair Bütünsel Bir Uygulama" Muhasebe ve Finansman Dergisi, Ocak (85), 1-24

Doğan, A. (2017). "Büyük ve Orta Boy İşletmeler için Finansal Raporlama Standardı ile TMS/TFRS Karşılaştırması", İşletme Araştırmaları Dergisi, No:4, 770-786 
Doğan, A. (2018). "Büyük ve Orta Boy İşletmeler için Finansal Raporlama Standardı ile VUK/MSUGT Karş1laştırması", Muhasebe ve Finansman Dergisi, 80(Ekim), 115-132.

Durmuş, C., N., Kutlu, O. (2020). "Büyük ve Orta Boy İşletmeler İçin Finansal Raporlama Standardının (BOBİ FRS), Türkiye Muhasebe Standartları (TMS) ve Türkiye Finansal Raporlama Standartları (TFRS) ile Karşılaştırılması", Mali Cozum Dergisi, 30(158), 189211.

Gökçen, G., Öztürk, E., Güleç, Ö., F. (2018). “BOBİ FRS ve TFRS'nin Finansal Raporlara Etkileri Açısından Karşılaştırılması" Finans Ekonomi ve Sosyal Araştırmalar Dergisi, 3(2), 437-457.

Gökçen, G., Öztürk, E., Güleç, Ö.,F. (2019). "KÜMİ FRS Seti Taslağı, BOBİ FRS Seti ve Tam Set TMS/TFRS'nin Temel Konular Açısından Karşılaştırılması”, Finans Ekonomi ve Sosyal Araştırmalar Dergisi, 4(3), 412-430.

Gökçen, G., Ataman, B., Çakıcı, C. (2011).Türkiye Finansal Raporlama Standartları Uygulamaları, Türkmen Kitapevi.

Gücenme, Ü. G. (2017). "Temel Konularda BOBİ FRS ve TMS/TFRS Karşılaştırması", Muhasebe ve Finansman Dergisi, 76(Ekim), 1-24.

Gücenme, Ü.G., (2020). "Küçük ve Mikro İşletmeler İçin Finansal Raporlama Standardı Taslağı nın BOBİ FRS ve Vergi Uygulamalarımız İle Karşılaştırılması ve Genel Değerlendirme" Business and Economics Research Journal, 11(1), 187-199.

Kamu Gözetimi Muhasebe ve Denetim Standartları Kurumu, Büyük ve Orta Boy İşletmeler İçin Finansal Raporlama Standard1. www.kgk.gov.tr

Kamu Gözetimi Muhasebe ve Denetim Standartları Kurumu, Türkiye Muhasebe ve Finansal Raporlama Standartları. www.kgk.gov.tr

Karaömer, Y., Özbirecikli, M. (2019). "Effects of Financial Reporting Differences in Between BOBI FRS and MSUGT on Financial Statement Analysis: An Investigation on Financial Structure Ratios", Muhasebe ve Finansman Dergisi, 84 (Ekim), 233-250.

Otlu, F., Güdelci, E., N. (2019). “ BOBİ FRS ile Ortaya Çıkması Muhtemel Etkilerin Teorik Boyutta Değerlendirilmesi”, Uluslararası Sosyal Araştırmalar Dergisi, 12(66), 1118-1125.

Şen, İ., K., Özbirecikli, M. (2018). "BOBİ FRS'nin Muhasebe Uygulamalarına Getirdiği Değişiklikler: BOBİ FRS, TMS/TFRS ve Mevcut Muhasebe Sistemi Çerçevesinde Bir İnceleme", Muhasebe ve VergiUygulamaları Dergisi, Nisan Özel Sayı, 462-484.

Şen, İ., K., Özbirecikli, M. (2020). "KÜMİ FRS'nin İş Dünyasına Sağlayabileceği Yararlar: BOBİ FRS, TMS/TFRS ve Mevcut Muhasebe Sistemi ile Mukayeseli Bir İnceleme", Muhasebe Bilim Dünyası Dergisi, Özel Sayı, 1-19.

Yazıcı, M. (2003), "Muhasebe Standardının Tanımı”, Muhasebe ve Finansman Dergisi, Sayı: 18, 33-37. 